\title{
Dever e prazer no casamento- empresa:transações regulares de controle do amor segundo a Igreja Universal
}

\author{
Bárbara Regina Altivo
}

Resumo: O trabalho sonda as principais linhas de sentido que animam a proposta da Igreja Universal do Reino de Deus (IURD) sobre o amor no mundo contemporâneo através de suas materialidades discursivas. O artigo aborda os discursos iurdianos de teor pedagógico sobre amor, família e gênero. Como característica deste aparato, observamos a associação direta entre a busca imediata pela obtenção da felicidade, característica do hedonismo presente na Teologia da Prosperidade, e um ascetismo de ordem empresarial, que visa domesticar as impulsividades emocionais do homem e, principalmente, da mulher, nas dinâmicas intricadas do relacionamento amoroso. Assim, podemos entrever linhas de força que conflagram subjetividades marcadas por compromissos de gênero inscritos num modelo familiar de inspiração mercadológica.

Palavras-chave: comunicação e Religião; Igreja Universal do Reino de Deus; análise de conteúdo discursivo; amor; negócio; gênero e sexualidade; casamento-empresa.

Abstract: Duty and pleasure in wedding-company: Regular transactions of love control according to the Universal Church - This paper investigates the central notions that animate the proposal of the Universal Church of the Kingdom of God (UCKG) about love in the contemporary world through their discursive materials. The article discusses the pedagogical content of UCKG's speech about love, family, and gender. As characteristic of this apparatus of power-knowledge-pleasure, we observe the direct association between the immediate pursuit of obtaining happiness. This feeling marks the hedonism present in Theology of Prosperity, and an asceticism of business order, which aims to domesticate the emotional impulses of man and mainly of women, into the intricate dynamics of the romantic relationship. Thus, we can glimpse lines of force that create subjectivities marked by gender commitments in a family model of marketing inspiration.

Keywords: communication and religion; Universal Church of the Kingdom of God; dicoursive content analysis; love; business; gender and sexuality; wedding-company. 


\section{Introdução}

É notável o crescente esforço da Igreja Universal do Reino de Deus (IURD) e de outras denominações evangélicas em produzir discursos pedagógicos, propostas pragmáticas e ações mágico-religiosas em torno da vida amorosa contemporânea, tida como um problema. A busca por informações no que tange às relações amorosas alimenta atualmente um enorme arranjo móvel de associações entre discursos variados, na qual interagem, com destaque, prerrogativas religiosas e a indústria de autoajuda. São vários livros, produções audiovisuais, programas televisivos e radiofônicos, eventos, cultos e cursos que tratam dos desafios de viver a dois, oferecendo conselhos e métodos de resolução de conflitos a partir de determinadas perspectivas sobre o casamento, a família e a relação entre homem e mulher.

A Universal é uma das grandes produtoras de materialidades discursivas sobre o amor, através de sua marca The Love School, encabeçada por Cristiane Cardoso, filha de Edir Macedo, e seu marido e bispo da Universal, Renato Cardoso. O casal, que morava no Texas, Estados Unidos, onde Renato administrava a sede americana da IURD, transferiu-se para o Brasil em 2011 com o intuito de produzir e gerenciar "um projeto disciplinar para casamentos e relacionamentos como um todo" (TEIXEIRA, 2012, p.120). O projeto reúne várias atividades: a publicação de livros e DVDs, o programa televisivo semanal da Rede Record The Love School - A Escola do Amor, cursos presenciais com casais e solteiros, o evento The Love Walk - A Caminhada do Amor, camisetas e outros produtos da marca, além do Cruzeiro The Love School, viagem de tema romântico com a presença do casal Cardoso.

Para fundamentar a discussão em torno destas iniciativas, concebendo a importância da conjugalidade na constituição de relações sociais e erótico-afetivas, primeiramente levantamos possíveis conexões teóricas entre o amor, em sua faceta romântica, e a vida familiar que se consolidou como modelo hegemônico no mundo ocidental moderno. Atentamos para os vetores de poder participantes de tal configuração, observando os mecanismos históricos de controle do afeto e do prazer nos relacionamentos amorosos heterossexuais. Nesse sentido, com base na noção foucaultiana de dispositivo de saberpoder-prazer, analisaremos os discursos da Igreja Universal de teor pedagógico sobre amor, família e gênero, associados à proposta pragmática de gerenciamento empresarial dos relacionamentos e à produção de uma economia de prazeres específica, fundada no compromisso com uma vida em abundância'.

Destarte, perscrutaremos as principais linhas de sentido que animam a proposta da Universal sobre o amor, através do contato com materiais discursivos, mais especificamente com o best-seller Casamento Blindado - O seu casamento à prova

1 As reflexões contidas neste artigo fazem parte de um dos aspectos desenvolvidos na dissertação de mestrado "O amor no rastro do mal: conjugalidade, família e o feminino demoníaco na perspectiva da Igreja Universal" (ALTIVO, 2015), elaborada no âmbito do Programa de Pós-Graduação em Antropologia Social da Universidade Federal de Minas Gerais (PPGAN-UFMG). Além disso, uma versão anterior do texto foi apresentada no GT Comunicação e Sociabilidade no $24^{\circ}$ Encontro da Compós, em Brasília, 2015. Agradeço a todos os membros do grupo pelas contribuições para com este trabalho. 
de divórcio, escrito por Cristiane e Renato. Notam-se, como ideias norteadoras da sua perspectiva: 1) a defesa iurdiana da fé inteligente, conceito aparentemente paradoxal que vincula o comprometimento religioso com uma postura racional de resolução de problemas, como norteadora das relações amorosas; 2) a lógica de um casamento-empresa, que controla as emoções dos cônjuges em prol de um matrimônio estável, duradouro e materialmente próspero; 3) a reafirmação de uma diferença natural entre homem e mulher, que coloca o masculino na esfera da razão e a mulher no polo dos afetos; bem como uma 4) blindagem do casamento contra diferentes tipos de ameaças do mal, tanto espirituais quanto psicológicas e sociais.

Apontamos, por fim, as operações regulares da Universal que articulam um discurso conservador, de ordem religiosa, sobre o que seriam os papéis biblicamente determinados de homem e mulher, e uma concepção mercadológica do relacionamento e da vida familiar, que propiciaria bem-estar emocional e financeiro, aspectos configuradores de um relacionamento feliz. No centro de sua argumentação, encontra-se a associação direta entre a busca imediata pela obtenção da felicidade, característica do hedonismo presente na Teologia da Prosperidade, e um ascetismo de ordem empresarial, que visa domesticar as impulsividades emocionais de homem e, principalmente, da mulher, nas dinâmicas intricadas do relacionamento amoroso. Assim, podemos entrever linhas de força que conflagram subjetividades profundamente marcadas por compromissos de gênero inscritos num modelo familiar de inspiração mercadológica.

\section{Nas tramas criativas do poder: sexualidade, amor e família}

Em sua análise da configuração moderna do amor, Viveiros de Castro e Bezaquien de Araújo (1977) tomam como narrativa paradigmática a história de Romeu e Julieta, de franca vocação popular, que acabou por tornar-se matriz ficcional na indústria cultural. A noção de amor que vigora neste texto demarca uma concepção específica de relações entre sociedade e indivíduo, direito e afeto, na qual a centralidade está no "indivíduo liberto de laços sociais, não mais derivando a sua realidade dos grupos a que pertencem, mas em uma relação direta com um cosmos composto de indivíduos, onde as relações sociais valorizadas são as relações interindividuais" (Ibid, p. 131). A oposição família versus amor é central na narrativa. Uma psicologia do amor substitui uma sociologia da aliança. Dessa forma, a premissa romântica das relações amorosas não se compromete com determinantes sociais, mas segue os impulsos emocionais dos indivíduos que se encontram predestinadamente para consolidar a promessa de felicidade plena. $\mathrm{O}$ amor torna-se direito do indivíduo, lócus de realização pessoal, elemento libertador que quebra a rotina e o dever (GUIDDENS, 1993, p.50).

No processo de domesticação do amour passion, como explica Lobato (2012), o matrimônio surge como promessa de legitimação e estabilização da relação apaixonada, 
o que engendra, desde já, o principal paradoxo que o amor romântico produz e luta para ultrapassar. Alocado na relação conjugal, o amor romântico traz a afetividade para dentro do casamento e o sagra como o único critério legítimo na constituição e manutenção do casal. Ao passo que, para isso, declina de suas características transgressoras para se ajustar às lógicas sociais da diferenciação de gênero e da aliança familiar (FONSECA, 1995; GUIDDENS, 1993; ABOIM, 2009).

A consolidação do afeto como elemento localizado nas famílias relaciona-se ao processo moderno de formação da esfera privada, como apontam diferentes estudos historiográficos (dentre eles, ELIAS, 1993; SENNETT, 2010; ARIÈS, 1981; SHORTER, 1995). O formato nuclear, centrado nas relações pai-mãe-filhos, se firma como "quente abrigo da domesticidade que protege da noite fria e inóspita", verdadeira "fortaleza emocional para onde a família moderna se retirou", clima emocional privilegiado que deve ser protegido de intrusões externas através da privacidade e do isolamento (SHORTER, 1995, p. 221). A sexualidade é, destarte, encerrada no lar, a família conjugal a confisca. "No espaço social, como no coração de cada moradia, um único lugar de sexualidade reconhecida, mas utilitário e fecundo: o quarto do casal" (FOUCAULT, 1999, p. 10).

Contudo, este modelo familiar contraído e centrado na relação conjugal, como mostram os dados históricos, não se desenvolveu de forma equânime nas sociedades capitalistas, mas mobilizou-se, principalmente, através do circuito matrimonial de minorias privilegiadas, grupos econômicos favorecidos (ARIÈS, 1981). É importante ressaltar o caráter normativo que esse tipo de organização da família passa a desempenhar, atrelado a interesses econômicos e políticos, a partir do século XIX. Considerado, numa perspectiva evolucionista, como o formato de família "mais humano da história", condizente com o "progresso da civilização", o ideal da família moderna nuclear se transforma em uma "norma hegemônica implícita que, adotada pela classe média, está sendo também direcionada aos grupos populares, cuja configuração familiar abarca não só o casal, mas sim o grupo inteiro de parentesco" (FONSECA, 1995, p. 74).

Não concebemos aqui, portanto, a família como instituição social estabelecida, pronta, célula passiva da vida em sociedade. Também não nos detemos na explicação da família como mecanismo opressor ou como mero poder de interdição. Perpassada por diferentes linhas de força, entendemos que a família ocidental moderna se constitui no jogo de interesses que conformam relações de saber-poder-prazer, na concepção de Michel Foucault (1999). Lócus primordial do afeto na modernidade, o núcleo familiar não deve ser encarado apenas como instituição formal, mas também como "fator capital de sexualização", mecanismo permutador da sexualidade com a aliança matrimonial que "transporta a lei e a dimensão do jurídico para o dispositivo da sexualidade; e a economia do prazer e a intensidade das sensações para o regime da aliança" (FOUCAULT, 1999, p. 103).

Por tal posição nevrálgica, que engendra repressão e prazer, a família, assim como a sexualidade, tem sido alvo de diferentes aparelhagens discursivas modernas com 
pretensões de verdade, pelas quais se multiplicam enunciados que dizem sobre a ordem do mundo e prometem certo tipo de felicidade (Ibid, p. 82). A maquinaria moderna de produção de discursos sobre a sexualidade, da qual tratou Foucault, como é possível notar, tem cunho racionalista e se dedica a inserir no âmbito familiar a lógica de análise, contabilidade, de gestão utilitária das relações domésticas, visando o seu funcionamento segundo um padrão ótimo (lbid, p. 27).

Como todo modelo normativo, a família nuclear burguesa tem de enfrentar variadas forças desestabilizadoras do seu formato e da ordem de mundo à qual defende e atualiza. Elisabeth Roudinesco (2003) ressalta os conflitos, as desproporções e temores que marcam o árduo labor de produção e manutenção do modelo familiar moderno, que hoje disputa espaço com inúmeras resistências, fragmentações e hibridismos. Em choque com a multiplicação de novos modelos familiares, forma-se um grande terror conservador.

\section{O amor como problema em Casamento Blindado}

Exemplo contemporâneo de investida discursiva sobre o amor, destacamos as produções da Igreja Universal em sua marca Love School. Em julho de 2012, como resultado do curso Casamento Blindado - seu casamento a prova de divórcio, o casal iurdiano Cristiane e Renato Cardoso lançou o livro de mesmo nome, que reúne as principais lições para a resolução de crises no casamento. O best-seller, - que conta com mais de um milhão de exemplares vendidos, com uma versão em inglês lançada em 2013, A Bulletproof Marriage - Making Your Marriage Divorce-Proof, e uma adaptação televisiva como especial de fim do ano da Record em 2013 -, é hoje a principal referência bibliográfica dos sacerdotes e fiéis da Igreja Universal sobre o tema dos relacionamentos amorosos ${ }^{2}$.

Assim, enquanto modelo discursivo por excelência evocado em diferentes contextos iurdianos quando o assunto é amor, tomaremos Casamento Blindado enquanto uma verdadeira força que atua no regime doutrinário da IURD no que tange ao tema dos casamentos, agente textual e modelo teórico-prático de comportamento participante das dinâmicas de falar e viver relacionamentos amorosos. O livro, mais do que apenas uma leitura sobre o amor, através de suas lições e propostas pragmáticas, incita as pessoas fazerem muitas coisas em seus relacionamentos. Por isso, queremos aqui passar por alguns de suas principais conceituações e dicas comportamentais, de modo a nos aproximarmos das concepções nativas sobre amor, família e relações amorosas entre homens e mulheres.

O livro estrutura-se em quatro partes, cada uma delas subdividida em vários capítulos. A primeira chama-se Entendendo o casamento (C. CARDOSO e R. CARDOSO, 2012, p. 23), onde os autores justificam a necessidade de "blindagem" dos relacionamentos hoje,

2 Em trabalho de campo desenvolvido na dissertação (ALTIVO, 2015), entrevistamos diferentes pastores e casais de fiéis da Igreja Universal que nos contaram sobre a importância de Casamento Blindado em seus relacionamentos. Estes interlocutores nos disseram que passaram a praticar as normas de conduta prescritas no livro, citando por diversas vezes algumas de suas ideias centrais, sobre as quais nos debruçaremos nesta sessão. 
por meio de uma apreciação crítica do que eles nomeiam casamento na era do Facebook, contexto de crescimento de divórcios e uniões efêmeras marcado por degenerações dos papéis naturais de homem e mulher, marido e esposa. A seguir, o livro trata do tema Razão vs. Emoção (Ibid, p. 57), desenvolvendo uma proposta metodológica de enfrentamento aos problemas conjugais embasada na homologia completa entre gerenciamento empresarial e o cuidado diário com o casamento, proposta na qual a razão é colocada como único caminho de enfrentamento sistemático às crises do relacionamento. Na terceira parte do livro, Desmontando e remontando o amor (Ibid, p. 117), os autores elaboram exegese do mito bíblico de Adão e Eva, de modo a fixar as atribuições ontológicas de homem e mulher, o que seria a essência do masculino e do feminino, em termos de maldições desencadeadas na Queda. Por fim, na quarta parte do livro, intitulada Fazendo a blindagem (Ibid, p. 183), Renato e Cristiane, levando em consideração a dupla dificuldade relacional do casamento até então apresentada - as ameaças da cultura contemporânea e a diferença fundamental homem versus mulher -, propõem uma série de dicas e soluções práticas para cada um dos integrantes do casamento, visando a manutenção do cuidado de si e do outro no seio da convivência matrimonial. Passemos mais detidamente pelas ideias do livro.

\section{O projeto de Deus para os relacionamentos}

No livro de Cristiane e Renato, é dito que Deus criou o homem e a mulher para viverem juntos em matrimônio, e que a realização pessoal de ambos, a sua felicidade, depende disso. Deus planejou a união plena de homem e mulher como um só corpo, a fusão complementar de dois seres em uma relação de amor propiciadora da formação familiar, tal como consta na harmonia edênica primordial.

Na parte Desmontando e remontando o amor, os autores afirmam que a família, célula social por excelência, engloba em si uma tensão insuperável: a união, "em uma só carne", entre dois indivíduos naturalmente diferentes, o homem e a mulher. O casamento é constituído, em última instância, pela diferença mais elementar da cosmogonia edênica. Adão e Eva foram criados por Deus, de início, para viver em harmonia. Entretanto, a famosa Queda deflagrou o princípio do conflito, da diferença radical, que determinou que homem e mulher tomassem lugares simetricamente opostos na relação. O homem foi amaldiçoado como escravo da natureza, o que se desdobrou na atual vinculação do masculino ao mundo do trabalho, ou seja, na tarefa de prover condições de subsistência material ao lar. Já a mulher, por sua vez, coube ser liderada pelo homem, organizadora nata do mundo doméstico, princípio aglutinador de pessoas, predisposição feminina a ser a "arquiteta dos relacionamentos", nas palavras do Bispo Renato. Se o homem foi criado da natureza e Eva surgiu da costela de Adão, "como resultado da maldição, homem e mulher foram sujeitados aos elementos de onde foram criados: o homem ficou sujeito à terra e a mulher, ao homem." (C. CARDOSO e R. CARDOSO, 2012, p.119). 
O homem é alocado segundo a sua função de produzir coisas, gerenciar racionalmente a vida, trabalhar e gerar conhecimento; ao passo que a mulher, por sua vez, deve atuar na constituição de pessoas (pela maternidade e pelos cuidados com a manutenção dos corpos familiares) nas relações de afeto e emoção que configuram o ambiente acolhedor do lar. A dicotomia natureza/cultura, emoção/razão, afeto/direito, segundo Casamento Blindado, apresenta-se, assim, sentenciada na Queda: homem e mulher em lugares opostos, sendo do primeiro o posto de liderança, de cabeça do relacionamento.

Naturalmente programados para serem diferentes e complementares, homens e mulheres se digladiam cotidianamente no relacionamento devido as suas respectivas maldições. Os homens tendem a dar muita atenção ao trabalho, a serem pragmáticos e diretos, na lógica uma caixinha para cada coisa, deixando de dar afeto e atenção à esposa. As mulheres, por sua vez, como uma bola de fios desencapados, são impulsivas e sentimentais, sofrem de insegurança com a negligência do marido. Diferentemente do poder de liderança tipicamente masculino, as mulheres seriam donas de um tipo diferente de poder, ligado à influência, à persuasão sedutora, diretamente herdada de Eva, força perigosa, a qual deve ser administrada segundo uma submissão com inteligência, o que explica Cristiane a suas leitoras:

Acredite: nós não precisamos liderar. Temos outra força, que é a influência. Com ela, podemos conseguir o que quisermos de nossos maridos. Esta influência nada mais é que a submissão feita com inteligência. Lembre-se, o homem já está "vendido" para a mulher. Ele almeja agradá-la. Por isso, o marido pode ser o cabeça, mas a mulher é o pescoço. E se for sábia, ela pode virar a cabeça para onde quiser... É tão assustador que temos que tomar cuidado com esse poder, para não destruirmos a nossos maridos e a nós mesmas. (C. CARDOSO e R. CARDOSO, 2012, p.197)

A filha de Edir Macedo é quem, na Universal, mais se dedica ao tema das mulheres na sociedade contemporânea, atuando como conselheira, palestrante e escritora especialista no assunto. Seus dois livros mais famosos, Melhor que comprar sapatos e A mulher $V$, propõem fundamentos espirituais, comportamentais e psicológicos para as mulheres virtuosas do século XXI. Modernas, à moda antiga, as mulheres de Deus devem ser criativas, alegres, educadas, batalhadoras e ótimas mães e esposas. O ideal é que sejam fortes e, ao mesmo tempo, femininas, que participem do mercado de trabalho sem deixar de lado as funções domésticas de cuidado do marido e dos filhos. Cristiane dirige o programa disciplinar para mulheres, chamado Godlywood, cujo objetivo é "o de levar as jovens a se tornarem mulheres exemplares e se tornarem avessas às influências e imposições Hollywoodianas. Elas desenvolvem laços familiares que tem se perdido nos últimos anos." ${ }^{\prime 3}$ No programa, através de desafios lançados por Cristiane e

3 <http://www.godllywood.com/br/como-surgiu-o-godllywood/> Último acesso em 30 de agosto de 2015. 
de encontros presenciais e virtuais, mulheres de diferentes faixas etárias participam de obras sociais da igreja, aprendem técnicas de cuidado com a aparência, organizam e executam afazeres domésticos, fazem leituras e estudos variados. (TEIXEIRA, 2012).

Renato, por sua vez, é quem fala diretamente com os homens da Universal, chamando-os para ocuparem novamente o lugar de cabeça do relacionamento, a se tornarem mais fortes e, assim, resgatar o respeito que perderam na sociedade. Em seus dizeres, ele sustenta que o homem forte reconhece as suas fraquezas - como a agressividade, o ciúme e o consumo de pornografia -, e as combate sistematicamente, de modo a se tornar um melhor marido e pai. É trabalhador, carinhoso com a mulher, romântico, mas sabe ter a palavra de decisão nos momentos difíceis, é quem toma para si os problemas da relação, sem medo, e se coloca à frente da mulher para protegê-la das hostilidades da vida. Assim como Cristiane comanda o Godlywood, Renato lidera o projeto disciplinar IntelliMen, mobilizando uma rede de homens "de 8 a 88 anos" a se ajudarem nos desafios de convivência com as mulheres modernas, no cenário de crescente enfraquecimento da presença masculina no núcleo familiar ${ }^{4}$.

Para eles, contudo, se as diferenças essenciais de homem e mulher já são problemáticas para qualquer relacionamento, no mundo contemporâneo as instabilidades e conflitos no casamento se agravaram fortemente, ameaçando o valor sagrado do matrimônio. Renato e Cris partem de um quadro que eles consideram alarmante a respeito do atual processo de metamorfose do casamento, que tende a intensificar-se ao longo dos anos. Nas palavras dos autores, isso significa, na prática, que:

O número de casamento diminuirá consideravelmente;

A "união livre" ou "estável", marcada por um conceito de que o compromisso duradouro e absoluto não é possível, será mais comum;

Infidelidade e traições aumentarão (sim, ainda mais) e se tornarão mais perdoáveis;

Encontros casuais com terceiros apenas para fins de sexo serão mais aceitos;

Homens e mulheres se tornaram ainda mais predadores;

O homem passará a ser dispensável para as mulheres que se verão mais independentes;

Mulheres oscilarão entre a descrença total no amor (e nos homens) e a busca pela felicidade, à custa de sua própria desvalorização

(C. CARDOSO e R. CARDOSO, 2012, p.25).

Diante do cenário turbulento das relações amorosas nos dias atuais, recheado de hibridismos e inversões de gênero, de valores anticasamento e da proliferação de formações familiares as mais variadas, uma verdadeira crise dos modelos comportamentais de gênero, a Igreja Universal, através de Cristiane e Renato, desenvolve uma empreitada de purificação dos papéis naturais de homem e mulher (LATOUR,1994), através de

4 <http://www.renatocardoso.com/wp-content/uploads/2013/01/IntelliMen-Manifesto1.pdf> Último acesso em 30 de agosto de 2015. 
várias ações de cunho pedagógico civilizador (ELIAS, 1990), como o próprio nome Love School indica. Destaca-se no discurso iurdiano sobre a vida amorosa, assim, o terror conservador do qual fala Roudinesco (2003). Como resposta às inversões e subversões de gênero e de formatos familiares na contemporaneidade, tal posicionamento assume uma postura de vitimização do pai, aquele que teria perdido o seu posto de líder e força da vida familiar. Renato chega a dizer que "o homem, na tentativa de agradar a mulher, tem se tornado mais sensível, retraído na sua posição no casamento, se sentido desrespeitado pela mulher, e ás vezes descartável.", num cenário em que "a mulher tem se tornado mais como o homem, e o homem mais como a mulher. Bagunça e confusão total de papéis" (C. CARDOSO e R. CARDOSO, 2012, p.28). Como podemos notar, as variadas iniciativas da IURD sobre o amor (cultos, livros, eventos e programas televisivos) se esforçam para recuperar uma hierarquia de gênero capaz de fortalecer laços de compromisso, combatendo o que seria a frouxidão dos vínculos atuais.

Como demonstra a preocupação de Cris e Renato em estabelecer formas corretas do ser homem e do ser mulher, a Universal visa a formação de famílias nucleares estáveis, centradas na aliança matrimonial vinculada a uma "vida em abundância", marca da Teologia da Prosperidade, fundada na valorização da riqueza material imediata enquanto índice de bênção divina (MARIANO, 2003). A família é a instância de realização pessoal que deve ser tratada, segundo a perspectiva da IURD, com planejamento estratégico e embasamento bíblico, de modo a garantir a prosperidade e o bem estar na vida doméstica.

\section{A fé inteligente na vida a dois}

Como vimos, determinados os papéis estruturais de marido e mulher pela ordem de Deus e as ameaças contemporâneas que configurariam um diagnóstico sombrio à estabilidade conjugal, é preciso saber resolver os problemas que inevitavelmente acometem os relacionamentos, o que, na tese de Cris e Renato, requer uma postura racional e prática. "Emoção não é ferramenta para resolver problemas" (Ibid, p. 63). O casal chega a esboçar um fluxograma, nos moldes empresariais, do que eles chamam de "sete estágios do ciclo de problemas não resolvidos no casamento" (Ibid, p.58), a partir do qual buscam traçar, passo a passo, um plano de ação para o Casamento Ltda. Os sete estágios são: "desentendimento > debate > impasse > ânimos esquentam > egos feridos > frustação e cansaço > desistem até o próximo..."; o ciclo tende então a começar novamente. Essa é a proposta pragmática que alicerça o alvitre de autoajuda do livro: é preciso identificar o problema, buscar a sua solução e executar o acordo estabelecido por marido e mulher, da mesmíssima forma como se faz o gerenciamento de uma empresa.

A racionalização do relacionamento significa, além da solução estratégica de conflitos, a sua própria prevenção, na medida em que intenciona o controle das impulsividades danosas à relação, como a agressividade, os ciúmes e o adultério. 
Em Casamento Blindado, Renato e Cristiane ensinam homem e mulheres a controlarem as suas emoções através do raciocínio e da oração, contando como eles tiveram de estabelecer, cada um, o seu autocontrole nos momentos críticos do casamento. Sendo assim, vemos trabalhem juntas as dimensões da realização pessoal - a prometida felicidade no amor e prosperidade no lar - e da repressão, das normas que determinam interdições no campo erótico-afetivo, o que aponta para a própria eficácia do dispositivo de saberpoder-prazer (FOUCAULT, 1999).

A noção de amor que vigora em Casamento Blindado, nos programas e cursos de Cristiane e Renato, vincula-se a um planejamento familiar de estabilidade, durabilidade e abundância, através da contenção racional de emoções e do cumprimento de rígidos papéis de gênero dicotômicos: a mulher no polo do afeto e o homem no polo da razão. Vimos também que tal arranjo nuclear precisa ser blindado contra as tendências subversivas da contemporaneidade, deve ser protegido contra as forças que invertem e subvertem lugares, dissolvem dicotomias, que fazem eclodir desejos inconfessos, paixões não domesticadas.

\section{Apropriações do amor pela Universal: reflexões finais}

O posicionamento da Universal, enquanto produtora de discursos que defendem o modelo hegemônico da família nuclear, a diferenciação sexual homem-mulher e a retomada da liderança masculina no lar pela via da vitimização do pai, integra uma mobilização evangélica cada vez mais ampla, calcada no terror conservador diante da diversidade de experiências afetivas contemporâneas. A sua singularidade, entretanto, está na aberta defesa de um modelo de gerenciamento familiar de inspiração empresarial. Nesse sentido, destaca-se o incentivo iurdiano ao planejamento familiar via controle de nascimentos, através de métodos contraceptivos e mesmo o aborto, enquanto "recomendação diretamente ligada à disciplina familiar rumo à prosperidade" (TEIXEIRA, 2012, p7), tema que gera grande polêmica entre os religiosos brasileiros ${ }^{5}$.

Assim, em consonância com as reflexões foucaultianas, concebemos aqui que o policiamento da vida familiar na Universal se desenrola menos pelo rigor de proibições do que por meio de discursos úteis e públicos, que fazem circular uma economia específica de prazer e dever. A produção de saberes, de discursos e prédicas em torno da família hoje, conformando um campo de batalha - religioso e sócio-político, no caso do nosso problema de análise -, respondem, entre outras coisas, à irrupção de novos modelos familiares, à eclosão de prazeres específicos e sexualidades disparatadas, que se desencadeiam através

5 Todavia, como Teixeira explica, tal posicionamento de Macedo que articula toda uma retórica sobre direito e domínio da mulher sobre o seu próprio corpo, "mobiliza sentidos distintos do que fora expressamente defendido pelo campo de lutas do feminismo" (TEIXEIRA, 2012, p. 52). A desaprovação da Universal em relação ao movimento feminista, aliás, está expressa em diversas publicações oficiais de seus representantes, como no caso do livro Casamento Blindado que já abordamos anteriormente. Sobre o aborto, o que interessa aos propósitos de ação iurdiana sobre a família é, de fato, a execução de um planejamento que controle necessidades e gastos a serem despendidos para a manutenção do lar. 
de uma rede de mecanismos entrecruzados não só repressivos, mas altamente criativos e prazerosos (FOUCAULT, 1999).

Tangenciamos, portanto, as articulações de um dispositivo específico que se produz não apenas nas instâncias oficiais, nas falas de sacerdotes e lideranças, mas na própria experiência biográfica, na intimidade da vida sexual dos casais e em suas relações familiares. Esta configuração multidimensional caracteriza a força do poder disciplinar operado pela Igreja Universal, que se constitui nas microrrelações que colocam para funcionar uma rede de procedimentos e mecanismos, espécie de micropoder que se capilariza e penetra em todas as escalas relacionais.

Neste processo de contenção das emoções em prol da estabilidade do relacionamento, atuam linhas de força que visam domesticar a todo custo as forças minoritárias que pululam nas subjetividades dos seus fiéis, segundo uma concepção reducionista sobre o ser homem e ser mulher. Este trabalho de luta corpo-a-corpo contra as tendências desestabilizadoras é custoso e implica numa constante reafirmação discursiva sobre os perigos que assolam o amor e o que seria um casamento feliz. Enquanto agente religioso e sócio-político atuante nas relações de poder que perpassam o cenário público brasileiro, a Universal desenvolve - conjuntamente com seus fiéis - tais constructos, que, por sua vez, participam dos debates contemporâneos sobre os modos legítimos de vivência erótico-afetiva e constituição familiar.

A Universal, assim, se esforça para desenvolver mecanismos de poder disciplinar adequados ao ethos imediatista da Teologia da Prosperidade. Ela articula o hedonismo contemporâneo, a busca pela realização pessoal e desfrute dos bens materiais, à ascese racionalista que visa gerar uma vida de abundância através da lógica empresarial. O trunfo iurdiano parece estar justamente no seu trabalho de conciliação destas duas modalidades de ação, articuladas segundo uma apropriação e conversão utilitarista do desejo.

Bárbara Regina Altivo é doutoranda no Programa de PósGraduação em Comunicação Social da UFMG e pesquisadora no Grupo de Pesquisa em Imagem e Sociabilidade (GrisUFMG). Tem mestrado em Antropologia Social pela Universidade Federal de Minas Gerais (PPGAN-UFMG).

barbaraltivo@gmail.com

\section{Referências}

ALTIVO, B. O amor no rastro do mal: conjugalidade, família e o feminino demoníaco na perspectiva da Igreja Universal. Dissertação de Mestrado em Antropologia Social. Belo Horizonte, MG: Universidade Federal de Minas Gerais, 2015.

ARIÈS, P. História social da criança e da família. São Paulo: Zahar, 1981. 
CARDOSO, C. e CARDOSO, R. Casamento Blindado - O seu casamento à prova de divórcio. Rio de Janeiro: Thomas Nelson, 2012.

CARDOSO, C. A Mulher V: moderna, à moda antiga. Rio de Janeiro: Unipro, 2011.

Melhor que comprar sapatos: pérolas de sabedoria para a mulher espiritual. Rio de Janeiro: Unipro, 2007.

ELIAS, N. O processo civilizador: Uma história dos costumes (R. Jungmann, Trad. Revisão e apresentação Renato Janine Ribeiro). Rio de Janeiro: Jorge Zahar, 1993

FONSECA, C.. "Amor e família: vacas sagradas da nossa época." Família em processos contemporâneos: inovações culturais na sociedade brasileira. São Paulo: Loyola (1995): 69-89.

FOUCAULT, M. História da sexualidade I: a vontade de saber. Rio de Janeiro: Graal, 1999.

GUIDDENS, A. A transformação da intimidade. Sexualidade, amor e erotismo nas sociedades modernas. Unesp, 1993.

LATOUR, B. Jamais fomos modernos. Rio de Janeiro: Ed 43, 1994.

LOBATO, J. P. Antropologia do amor: Do Oriente ao ocidente. Belo Horizonte: Autêntica, 2012.

MARIANO, R. Neopentecostais: sociologia do novo pentecostalismo no Brasil. São Paulo, Loyola, 2003.

SENNETT, R. O Declínio do Homem Público: as tiranias da intimidade. Tradução: Lygia Araújo Watanabe. São Paulo: Companhia das Letras, 1999.

SHORTER, E. A formação da família moderna. Lisboa: Terramar, 1995

TEIXEIRA, J. M.. Da controvérsia às práticas: conjugalidade, corpo e prosperidade como razões pedagógicas da Igreja Universal. Dissertação de Mestrado em Antropologia. São Paulo, SP: Universidade de São Paulo, 2012.

VIVEIROS DE CASTRO, E. e ARAúJO, R. B. "Romeu e Julieta e a Origem do Estado". In: G. Velho (org.), Arte e Sociedade: ensaios de Sociologia da Arte. Rio de Janeiro: Zahar, 1977, p.130-169. 